\title{
Long-term budget planning in the context of globalization and its socio-economic significance
}

\author{
Vitaliy Fedosov ${ }^{1}$, Galina Morunova ${ }^{1,{ }^{*}},{\text { Natalia } \text { Ivanova }^{1} \text {, and Marzhinat Kankulova }}^{1}$ \\ ${ }^{1}$ Saint Petersburg state University of Economics, Faculty of Economics and Finance, Department of \\ Finance, 21 Sadovaya str., Saint Petersburg, Russia
}

\begin{abstract}
.
Research background: The process of globalization increases the possibility of a more equitable distribution of income and national wealth, which contributes to the solution of social problems and ensures the development of the material base of human potential. In these conditions, the issues of budget planning of mandatory budget expenditures for the social sphere, in particular for education. With the use of simulation modeling, it is possible not only to implement budget planning more effectively, adjust current social expenditures, but also to increase the horizon of long-term budget planning, which is especially important in conditions of high financial dependence.

Purpose of the article: to study the use of simulation modeling for longterm budget planning of mandatory budget expenditures in the social sphere at the subnational level.

Methods: we have researched based on the application of the "Any Logic" modeling method for long-term budget planning and adjustment of current social expenditures.

Findings \& Value added: the study conducted by the authors allows us to conclude that the use of "any logic" for long-term financial planning in the context of globalization makes it possible for States to model social expenditures in the current and future periods. Based on official statistics, the forecast model of mandatory budget expenditures for the social sphere takes into account various factors (changes in demography, the number of recipients of social services, etc.) and provides a forecast of socioeconomic development. Long-term budget planning based on simulation models allows you to adjust current social programs, which will improve the quality of life in the context of globalization.
\end{abstract}

Keywords: budget planning; simulation; social expenditures; globalization

JEL Classification: $C 53 ; E 27 ; H 61 ; H 72 ; H 77 ; O 2 O$

\footnotetext{
* Corresponding author: morunova2009@mail.ru
} 


\section{Introduction}

Public finance management is aimed at improving the well-being of the population. Budget planning is an important element of public finance management. With the help of sound long-term budget planning of expenditures, it is possible to achieve higher indicators of socio-economic development. Simulation modeling makes it possible to carry out long-term budget planning more effectively and has variability due to the ability to adjust budget indicators, which is especially important in the context of the globalized world economy.

Many researches of foreign authors consider the development of the long-term budgetary projection $[1,2]$. The study of long-term budget planning correlates with the analysis of various areas of budget relations. Some authors pay attention to the issues of pension funds, whose activities have a great impact on the entire financial sector. In some countries predominate state-managed pension funds, in other countries predominate private pension funds. But their activities must be taken into account in long-term budget planning [3].

A number of authors study the issues of fiscal policy [4] and taxation. For example, differences in the total labor supply of married couples in 17 European countries and the United States. The study is based on a model of joint decision-making by households. Taxes are the most important source of revenue for the budget, so you need to take into account all the factors that affect them [5]. A separate area of research is the taxation of rich citizens. Rich households may respond to taxation with means that are not economically feasible for the rest of the population [6].

The dynamics of the national currency exchange rate has a particular impact on budget planning. This is especially true for countries that depend on foreign economic conditions, such as the Russian Federation. The study of factors that affect the exchange rate was conducted by the authors on the 10 most traded currencies [7].

Long-term budget planning is carried out to achieve economic growth. Economic growth in the context of globalization can be achieved not only through fiscal policy measures, but also by creating conditions for business development. The digitalization of the economy leads to the formation of global social networks, which affects the long-term planning of the state [8]. Other authors study impact of globalization on the financial management processes [9, 10], social consequences of globalization [11], consequences of economic growth support [12], process modeling in the public sector [13, 14], budget analysis $[15,16]$, municipal borrowing costs and state policies for distressed municipalities [17]. Economic preferences also influence economic growth in the global economy. Preferences vary from country to country depending on aggregate outcomes, from per capita income to business activity to the frequency of armed conflict [18].

Russian authors also consider various aspects of long-term budget planning in the context of globalization, for example, programming socio-economic processes [19], the development of financial system of the Russian Federation in the conditions of globalization [20], world tendencies of globalization and specifics of national economic development [21], globalization and the prospects for developing countries [22], economic and institutional development of Russian regions in the context of the global socioeconomic processes [23], Russian economy growth modeling in the globalization period [24], analysis of the development of budgetary federalism and problems of budgetary decentralization [25], the project approach in budget planning [26], management of state and municipal finances in the transformational economy [27-29]. But the complexity of this topic leads to the need for more in depth research.

Long-term planning is regulated by the Federal Law "On Strategic Planning in the Russian Federation" (No. 172-FZ). In accordance with this law, the development and implementation of strategic planning documents, as well as the definition of long-term 
goals and objectives. Article 7 172-FZ establishes the principles of strategic planning: the principle of balance of the strategic planning system; the principle of resourcing; the principle of purpose-oriented programmes, etc. The main document of long-term budget planning (Article 170.1 of the Budget Code of the Russian Federation) is the budget projection, which is compiled for all levels of the budget. The budget projection of the constituent entity of the Russian Federation for a long-term period is developed every six years for twelve years or more.

\section{Methodology}

The article discusses the methods of long-term budget forecasting and planning used in national economies in the context of globalization. Different countries use different methods of budget planning. In addition to traditional planning methods, many countries base their budgets on long-term government programs. This was one of the prerequisites for expanding the budget planning horizon. In modern conditions of software development, it becomes possible to do budget forecasting and planning for several decades. The dynamics of budget indicators of the OECD countries and the Russian Federation at the national and subnational levels is analyzed in this research. Trends of centralization/decentralization of the budget systems of these countries are identified. In the course of the research, the possibilities of using various methods of long-term budget planning were considered, and the most effective method was chosen.

\section{Results}

The paper analyzes long-term budget planning in the Russian Federation and foreign countries. Factors influencing the use of this tool in budget policy are identified. In different countries there are different horizons of the long-term budget planning. In the United States, planning is carried out for up to 10 years, up to 25 years, and up to 75 years. In the UK, long-term budget plans are drawn up for up to 5 years and up to 30 years. From our point of view, it is advisable to plan for 2 periods: up to 10 years; over 10 years (or for an indefinite period). The use of software products allows you to achieve high accuracy in long-term budget planning. But more importantly, what planning methods are used. Simulation can improve the effectiveness of long-term budget planning at the national and subnational levels.

Over the past decade, the centralization of the budget systems of countries in the world has significantly increased. This is a consequence of the ability to reduce costs when implementing expenditures from the central budget, as well as the predictability of central budget planning. However, many studies show an increase in the efficiency of budget expenditures when the budget system is decentralized. The application of simulation modeling at the regional level using the AnyLogic software product has proven its effectiveness at the regional level in the Russian Federation. The extension of this practice will allow for more accurate long-term budget planning using various factors. In this case, subnational authorities will be able to implement their budget policies more effectively.

Long-term budget planning should be applied not only at the national level. The increased centralization of budget systems in countries around the world is a consequence, among other things, of the higher efficiency of revenue and expenditure planning by central government. Improving long-term budget planning at the subnational level will allow authorities to better implement budget policies. You can use AnyLogic to create long-term budget plans using simulation. The author's research proved the effectiveness of this software product in planning at the regional level. 
Modeling in the AnyLogic environment allows you to build a model of long-term budget expenditures in the social sphere (education, health, social policy, etc.). In addition, the use of the proposed simulation model for long-term budget planning allows you to increase the time horizon of planning for more than 20 or even 50 years. Such modeling will help to evaluate the decisions made and create a real basis for the implementation of long-term socio-economic programs.

\section{Discussion}

Starting from 2014, the budgets of the budget system of the Russian Federation are formed and executed based on the application of the program principle, which assumes the use of state programs as the main tool for budget planning. The use of program tools of budget planning leads to the question of what is the optimal extent of their coverage of the expenditure part of the budget, and which expenditures should be included in the program part of the budget, and which should be considered non-program. In the Russian Federation, this problem is compounded by the fact that budget legislation does not regulate the concept and content of program and non-program expenditures.

Structure of program expenditures should be determined by the strategic goals and objectives of socio-economic development within the list of expenditure obligations. The main problem is the quality of goal setting in the framework of state programs. Its implementation is associated with many methodological problems that remain unresolved within the framework of traditional approaches to programming now. Such problems include inconsistency between the strategic goals of socio-economic development and the goals of state programs, determining the optimal list of tasks for each specific program, and their coordination with target indicators.

Some of these problems can be solved by applying the project approach to the management of state programs. It allows you to abandon their complex hierarchical structure and make the goals of programs much more specific and measurable. In addition, simulation can be an important aspect of the realism of long-line budget planning.

The issues related to non-program budget expenditures are focused on two main issues - whether such expenditures should take place and, if so, what their composition should be.

In modern domestic practice, there are cases when the expenditure part of the budget, which does not fully consist of program expenditures, is considered as not optimal. Such comments are made by individual control and accounting bodies in the preparation of conclusions on budget plan. If we turn to foreign theory and practice, there is a point of view that the program classification should cover all non-interest expenses of the budget. However, this approach is not applicable to today's domestic realities due to the fact that the authority to approve state programs in accordance with the legislation of the Russian Federation belongs to the highest Executive authorities. Thus, the inclusion in the programs of expenses for the maintenance of bodies that are not part of the Executive branch inevitably entails either a violation of the principle of separation of powers, or a violation of the logic of the formation and functioning of the state program. The first situation occurs if the program for these bodies has approved indicators of results, the second-if such indicators, on the contrary, are not approved.

The methodology of long-term budget planning is gradually developing in the Russian Federation. But in comparison with some foreign countries, it has only recently started to be implemented in practice. Each state chooses its own way of developing long-term budget plans, which is determined by the objectives of the analysis, available statistics, and the specifics of socio-economic development.

Long-term budget plans abroad and in Russia are based on the forecast of socioeconomic development (scenario conditions), characterized by long-term values of 
macroeconomic indicators. Therefore, prior to their development, socio-economic indicators are analyzed and forecast in order to identify trends in macroeconomic development. During the development of a long-term budget forecast, the growth rate of real gross domestic product in previous years is analyzed, and the factors that caused this growth are determined.

The current budget legislation defines the types of expenditures and directions of spending budget funds. Therefore, long-term budget planning is based, among other things, on the existing features of budget relations. As a rule, states set mandatory expenditures. Their amount may depend on many factors. However, the amount of mandatory expenses must be planned based on the current legislation. The remaining expenditures are planned based on the macroeconomic forecast.

Simulation modeling of socio-economic indicators is used to improve the accuracy of long-term budget planning. This approach can improve the efficiency of budget planning. And with the appearance of new factors that significantly affect the model, they can be used in calculations, which will lead to changes in planned budget expenditures and revenues. In the context of globalization, long-term budget planning should take into account external risks that affect the development of the country's economy.

Given budget rules and assumptions about exogenous variables, simulation is performed in two stages: for a period of up to 10 years, and for a period of more than 10 years. For the first ten-year period, the equations are adjusted so that the modeled variables correspond to their values in the ten-year baseline projections obtained from the medium-term models. This adjustment is necessary because medium-term projections embody detailed information about the budget and economic development in the medium term, while the long-term model only defines the overall relationship in the long term. At the second stage of modeling (years after the first ten-year period), no adjustment is made to the economic equations. Therefore, the basic modeling corresponds to the basic medium-term projections and then extends them according to the model equations.

Budget simulation is a planning method in which public authorities receive a document that occupies an important place among the state's financial plans. Based on it, public authorities can make other financial plans, since the simulation uses legal restrictions and other assumptions about exogenous variables. In this alternative modeling, each equation is also subject to adjustments that are necessary to ensure that the design for the first decade meets the medium-term baseline parameters approved by the official authorities. The use of simulation modeling in budget planning allows you to create a budget for a long period of time using mathematical tools. Long-term budget planning is used by many countries now. Simulation modeling can be particularly effective in forecasting for 30-75 years.

Different countries use different budget planning periods. Governments started publishing their long-term financial plans not so long ago. But based on the analysis, we can say that the most common period of budget planning is 40-50 years. In South Korea, long-term budget planning is carried out for 25 years, in the USA - up to 75 years, and in the Netherlands - up to 100 years. Among the countries of the Organization for economic cooperation and development, more than half of the countries analyze the long-term state of public finances annually, five countries-on a regular periodic basis (every three to five years), and four countries - on a special schedule. Long-term budget forecasts are made at the supranational level, such as the International Monetary Fund.

Long-term budget planning plays a significant role in the budget policy. Using the example of the OECD and the Russian Federation, it can be seen that most of the GDP is redistributed through the budget systems of countries (Figure 1). 


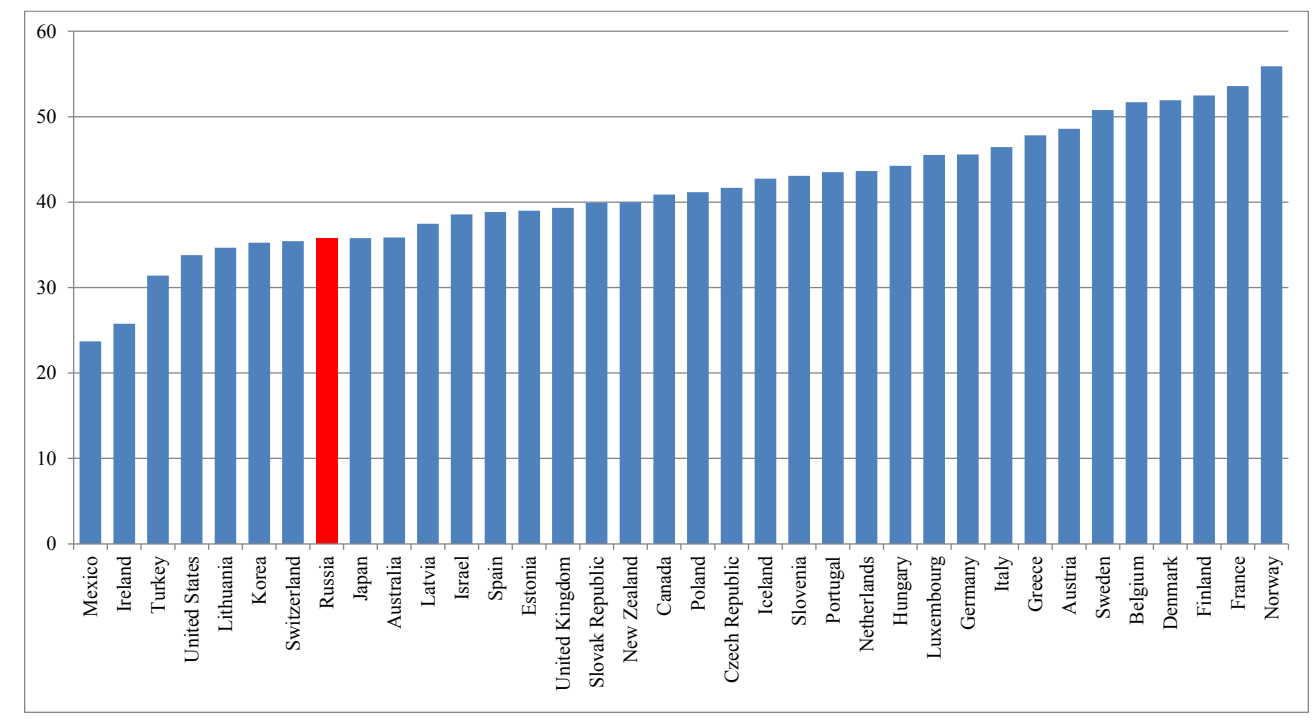

Fig. 1. General government revenues for 2018, as a percentage of GDP Source: data of the OECD, Treasury of Russia, authors' calculations

The high share of general government revenues in GDP indicates the possibility of a strong state influence on the economy through fiscal policy. If the government implements long-term budget planning efficiently, it can contribute to the country's economic growth and improve the well-being of the population. The budget planning horizon depends on several factors, the most important of which are: the stability of economic and political development; the detail of planned indicators; and the traditions of financial planning. With the development of software, you can use more complex planning methods and implement it for a longer period of time. In addition, it is possible to expand the budget planning horizon not only at the national level, but also at the subnational level. At the subnational level, long-term budget planning in the Russian Federation has only recently begun to be implemented. In modern research, budget decentralization, in addition to traditional directions, is considered as a factor that stimulates economic growth. Although there are no unambiguously confirmed results of the presence of a direct relationship, some authors indicate its presence. The thesis of a constant increase in the decentralization of budget systems is confirmed in practice only for individual states. The dynamics of the share of subnational government revenues in the general government revenues for the period 20092018 is shown in Figure2. 


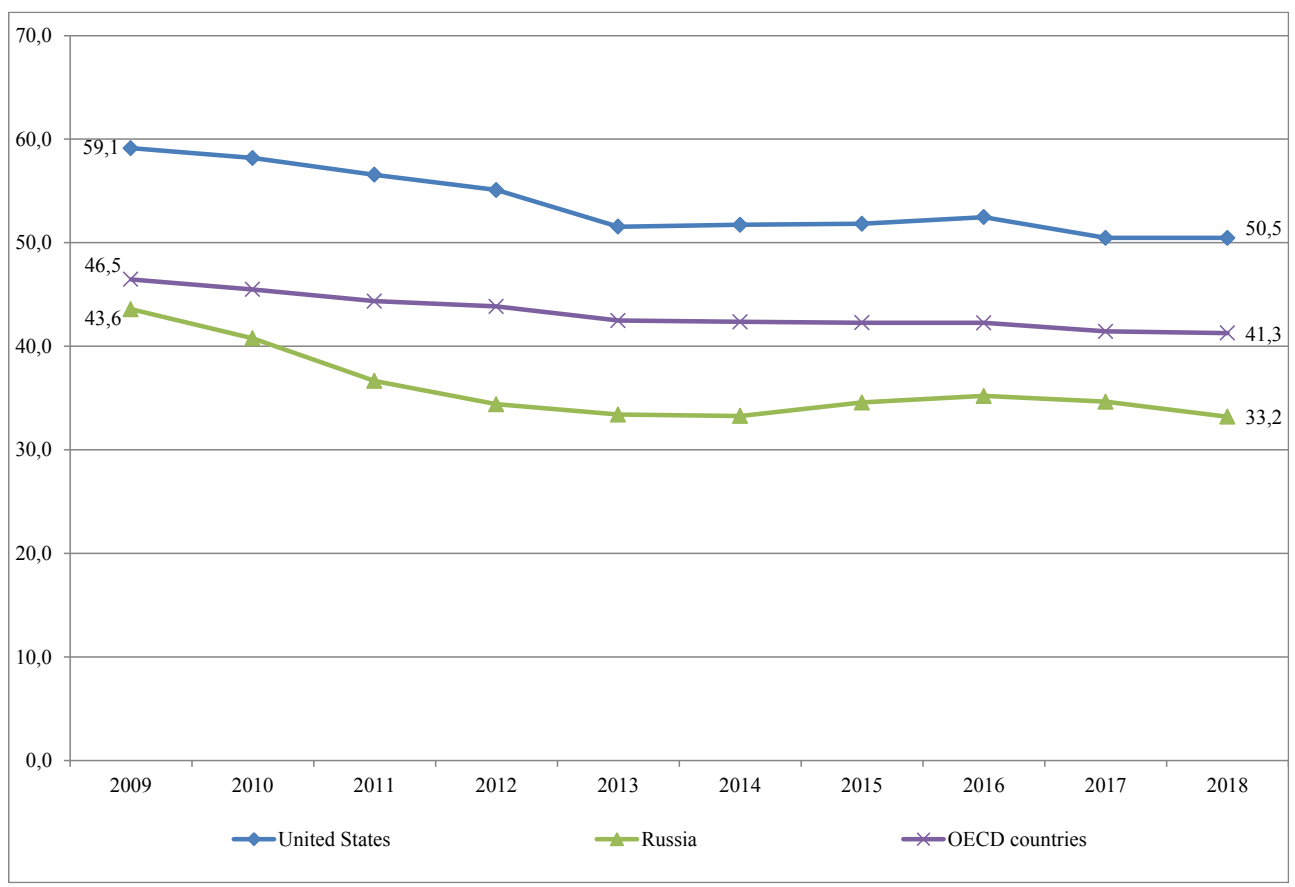

Fig. 2. Subnational government revenues of the OECD countries and the Russian Federation for 2009-2018, as a percentage of general government revenues

Source: data of the OECD, Treasury of Russia, authors ' calculations

The decentralization of subnational budget revenues decreased from $46.5 \%$ in 2009 to $41.3 \%$ in 2018 across all OECD countries. Of course, these countries are very different from each other. Among them there are both unitary and federal states. It is obvious that budget systems in federal states are on average more decentralized due to the presence of another level of governance - regional. The share of subnational government revenues in the general government revenues for the OECD federal states for the period under review predictably exceeds the average, but it fell even more - by 5.5 (from $56.9 \%$ to $51.4 \%$ ). At the same time, different countries show different trends. If in the United States for 20092018 the level of decentralization of the budget system decreased very seriously - by 8.6 p.p., in Germany it increased by 2.4 p.p. The level of decentralization of the budget system in Russia in 2018 was $33.2 \%$, which is significantly lower than not only the level of this indicator for federal states, but also for the OECD countries as a whole. At the same time, we can observe a negative dynamics of the indicator, which shows a decrease of 10.5 p.p. for the analyzed period.

The level of decentralization of the budget system in Russia in 2018 was $33.2 \%$, which is significantly lower than not only the level of this indicator for federal states, but also for the OECD countries as a whole. At the same time, we can observe a negative dynamics of the indicator, which shows a decrease of 10.5 p.p. for the period2009-2018 years. A comparison of the decentralization of budget relations across the OECD countries and Russia is shown in Figure 3. 


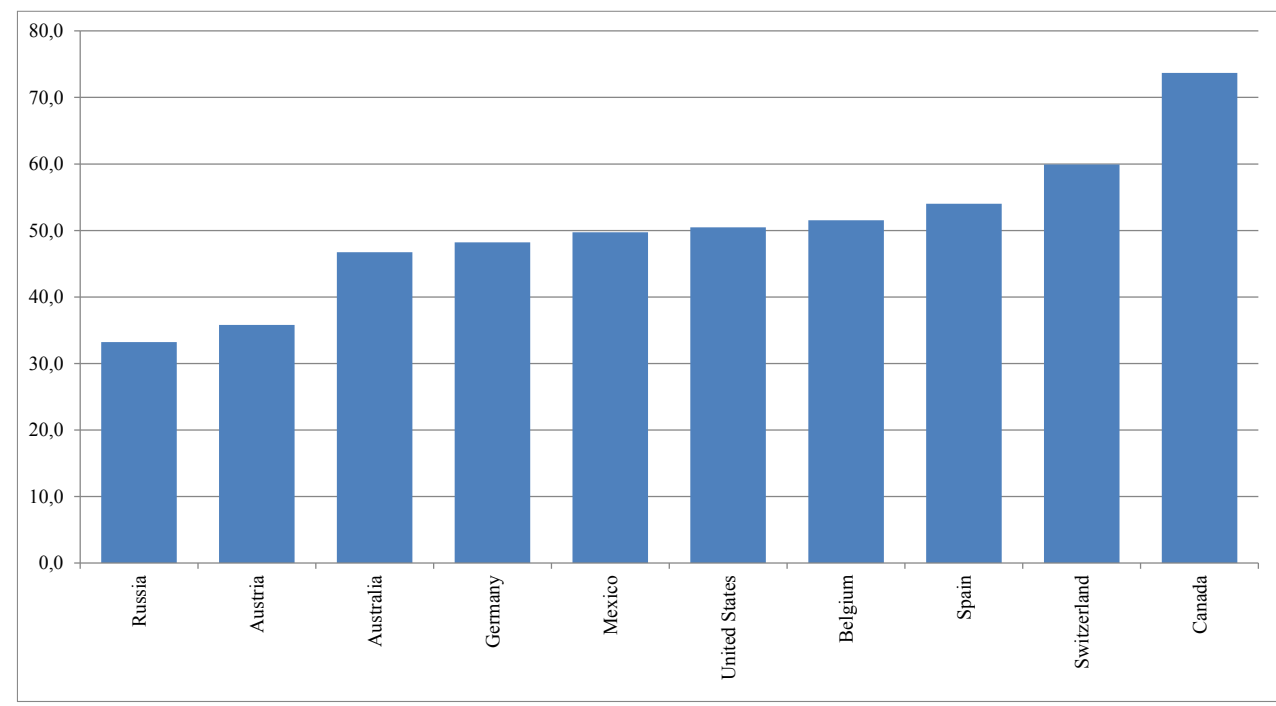

Fig. 3. Subnational government revenues of the OECD federal countries and the Russian Federation for 2018, as a percentage of general government revenues

Source: data of the OECD, Treasury of Russia, authors ' calculations

The level of the Russian economycentralization is higher than in all the OECD federal states. It can also be noted that most of the OECD countries are unitary. Some of them have a quite centralized budget system (Figure 4).

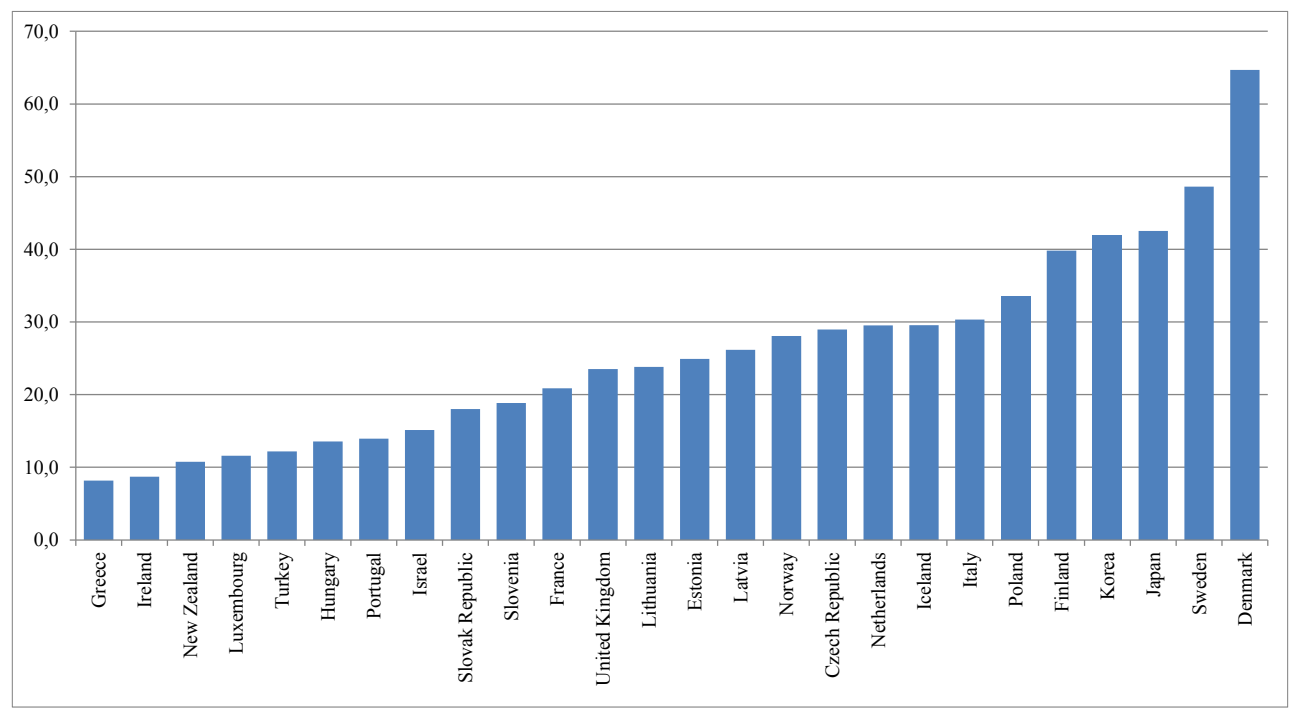

Fig. 4. Subnational government revenues of the OECD unitary countries for 2018 , as a percentage of general government revenues

Source: data of the OECD, authors ' calculations

The duration of long-term budget planning varies from country to country. In the United States, the long-term budget forecast at the Federal level is made for 10 years. When forming the budget for 2020, the forecast values for the period 2020-2029 are given. A number of indicators are projected for a period of 25 years, and some parameters-for 75 years. In the UK, budget planning is carried out for 5 years at the state level. For individual 
indicators, data is provided for the period up to 30 years. In Germany, the Federal budget is drawn up for 3 years. A number of indicators are projected for a longer period.

An analysis of the OECD countries showed that they carry out budget forecasting over a long period of time, but on the basis of consolidated budget indicators. Thus, the foreign experience of building budget forecasts up to 10 years with detailed indicators and forecasting for a period of 20 years or more on exogenous indicators using simulation modeling can be applied in Russia.

Long-term budget planning should be applied not only at the national level. The increasing centralization of budget systems in countries around the world is a consequence, among other things, of the higher efficiency of revenue and expenditure planning by central government. Improving long-term budget planning at the subnational level will allow authorities to better implement budget policies. You can use AnyLogic to create long-term budget plans using simulation. The author's research proved the effectiveness of this software product in planning at the regional level in Russia.

\section{Conclusion}

Long-term budget planning is already well developed in some foreign countries. Much attention is paid to it in the Russian Federation at the national level. Long-term budget plans are also being developed at the regional and municipal levels in the Russian Federation. But they are usually of poor quality. Subnational budgets in the Russian Federation have a high level of financial dependence on the federal budget. Therefore, the implementation of long-term fiscal policy in these conditions is problematic.

In the context of globalization, countries are becoming more dependent on each other, and trade, capital and labor flows are increasing. This has a positive impact on national economies during a period of economic growth, but external shocks can have a negative impact on individual countries.

Long-term budget planning should consider all possible factors of development of the national economy. This is possible when using simulation modeling in planning. This area has not yet been fully explored, although there are already positive results. From our point of view, it is necessary to continue research on the use of simulation in long-term budget planning.

\section{References}

1. Anderson, B., Sheppard, J. (2009). Fiscal Futures, Institutional Budget Reforms and Their Effects: What can be learned? OECD Journal on Budgeting, 3, 7-116.

2. Krishnamurthy, A., Vissing-Jorgensen, A. (2015). The impact of Treasury supply on financial sector lending and stability. Journal of Financial Economics, 118(3), 571600 .

3. Andonov, A., Hochberg, Y.V., Rauh, J.D. (2018). Political Representation and Governance: Evidence from the Investment Decisions of Public Pension Funds. Journal Of Finance, 73(5), 2041-2086.

4. Bui, D.T. (2018). Nonlinear effects of fiscal policy on national saving: Empirical evidence from emerging Asian economies. Journal of Asian Business and Economic Studies, 25(1), 2-14.

5. Bick, A., Fuchs-Schundeln, N. (2018). Taxation and Labour Supply of Married Couples across Countries: A Macroeconomic Analysis. Review of Economic Studies, 85(3), 1543-1576. 
6. Landier, A., Plantin, G. (2017).Taxing the Rich. Review of Economic Studies, 84(3), 1186-1209.

7. Colacito, R., Croce, M.M., Gavazzoni, F., Ready, R. (2018). Currency Risk Factors in a Recursive Multicountry Economy. Journal of Finance, 73(6), 2719-2756.

8. Duernecker, G., Vega-Redondo, F. (2018). Social Networks and the Process of Globalization. Review of Economic Studies, 85(3), 1716-1751.

9. Grofcikova, J. (2017). Impact of globalization on the financial management processes. 17th International Scientific Conference Globalization and Its Socio-Economic Consequences (pp. 589-596).

10. Obstfeld, M. (2020). Two challenges from globalization. Journal of International Money and Finance, 110, 102301.

11. Semes, M. (2018). Social consequences of globalization. 18th International Scientific Conference Globalization and Its Socio-Economic Consequences (pp. 358-365).

12. Tesarova, V. (2018). Consequences of economic growth support in small open economy in a globalized world. 18th International Scientific Conference Globalization and Its Socio-Economic Consequences (pp. 413-420).

13. El, Araby, M.A., Ayaad, N.e.D.S. (2020). Dilemma of institutional performance assessment in governmental sector: A proposed KPIs model. Journal of Humanities and Applied Social Sciences, 2(2), 115-139.

14. Campbell, J.Y., Chan, Y.L., Viceira, L.M. (2003). A multivariate model of strategic asset allocation. Journal of Financial Economics, 67(1), 41-80.

15. Kasperskaya, Y., Xifré, R. (2020). The analytical capacity of budgetary administrations: the case of the Euro area. Journal of Public Budgeting, Accounting \& Financial Management, ahead-of-print (ahead-of-prin)t.

16. Chen, Z., He, Z., Liu, C. (2020). The financing of local government in China: Stimulus loan wanes and shadow banking waxes. Journal of Financial Economics, 137(1), 4271.

17. Gao, P. Lee, C., Murphy, D. (2019) Municipal borrowing costs and state policies for distressed municipalities. Journal of Financial Economics, 132(2), 404-426.

18. Falk, A., Becker, A., Dohmen, T., Enke, B., Huffman, D., Sunde, U. (2018). Global Evidence On Economic Preferences. Quarterly Journal of Economics, 133(4), 16451692.

19. Okrepilov, V., Makarov, V., Bakhtizin, A., Kuzmina, S. (2015). Application of supercomputer technologies for modeling socio-economic systems. Region economy, 42(2), 301-313.

20. Bulatova, A. (2017). The prospects of a financial system development of the Russian Federation in the conditions of globalization. 17th International Scientific Conference Globalization and Its Socio-Economic Consequences (pp. 218-225).

21. Zhulega, I., Samoylov, A., Budagov, A. (2017). World tendencies of globalization and specifics of national economic development. 17th International Scientific Conference Globalization and Its Socio-Economic Consequences (pp. 3084-3090).

22. Volkova, A., Kulakova, T., Koverzneva, S. (2017). Globalization and the prospects for developing countries: new development institutions. 17th International Scientific Conference Globalization and Its Socio-Economic Consequences (pp. 2911-2918).

23. Tabachnikova, M., Treshchevsky, Y., Frankovskay, G., Vertakova, Y., Sogacheva, O. (2017). Economic and institutional development of Russian regions in the context of 
the global socio-economic processes. 17th International Scientific Conference Globalization and Its Socio-Economic Consequences (pp. 2642-2649).

24. Klevtsova, M., Polozhentseva, Y., Leontyev, E. (2018). Russian economy growth modeling in the transformation conditions in the globalization period. 18th International Scientific Conference Globalization and Its Socio-Economic Consequences (pp. 1135-1142).

25. Ivanova, N., Morunova, G., Fedosov, V., Kuzmina, S. (2019). Fiscal decentralization: the search for new approaches for the development of local government. E3S Web of Conferences, 110, 01028.

26. Ivanova, N., Kankulova, M. (2019). State programme and project approach in budget planning in the Russian Federation. Journal "Economic sciences", 12(181), 13-20.

27. Morunova, G. (2016) Theory, legislation and practice of organizing municipal finance in the transformational economy. St.Pererburg: St.Petersburg State University of Economics.

28. Ivanova, N. (2018). Management of state and municipal finances: theory and modern practice. In N. G. Ivanova (Eds.). Saint Petersburg state University of Economics.

29. Morunova, G., Gorbushina, S., Okrepilov, V., Kuzmina, S. (2018). Sustainable development of municipalities: financial assurance infrastructure. MATEC Web of Conferences, 239, 08005. 